\title{
Analysis of a New Multi-Oscillated Current Resonant Type DC-DC Converter
}

\author{
Osamu MATSUO ${ }^{\dagger} \quad$ Hirofumi MATSUO $^{\dagger} \quad$ Yoichi ISHIZUKA $^{\dagger} \quad$ Hiroyuki OTA ${ }^{\ddagger} \dagger$ Graduate School of \\ Science and Technology, Nagasaki University,1-14, Bunkyo-machi, Nagasaki, 852-8521 Japan \\ †Fuji Electric Device Technology Co., Ltd. 4-18-1 Tsukama, Matsumoto-shi, Nagano-ken, 565-0456 Japan \\ E-mail: ${ }^{\dagger}$ osamu_matsuo@yahoo.co.jp, ${ }^{\ddagger}$ oota-hiroyuki@fujielectric.co.jp
}

\begin{abstract}
This paper presents the analysis of a new multi-oscillated current resonant type DC-DC converter. Current resonant converters have several remarkable features such as high efficiency, small size, low cost and low noise, and are frequently employed in many portable electronic systems such as personal computers, cellular phones and flat panel displays.

The current resonant type converter generally employs pulse frequency modulation for constant voltage control in the output. For this reason, the magnetizing current through the converter not only causes a power loss under a light load, but also a loss during stand-by.

Therefore, this type of converter has a problem in that the required smaller size cannot be achieved, because an auxiliary source is necessary for stand-by.

In order to solve these problems, a new current resonant type power supply is proposed in which two driving methods are employed. In these driving methods, one MOSFET as a main switch is driven by an auxiliary winding of the transformer and another MOSFET as a main switch is driven by the driving IC with a low withstand voltage.

Good agreement of the observed and simulated waveforms was confirmed. In addition, eight distinct states and four distinct operating modes, which compose of the sequence of states, were clarified by experimental and simulated analysis.
\end{abstract}

Key terms - Multi-oscillated, Current resonant DC-DC Converter, ZCS, ZVS

\section{INTRODUCTION}

A switching power supply system is required for high efficiency, small size, low noise and low cost, in many areas of portable electronics systems such as personal computers, cellular phones and flat panel displays. Current resonant type converters in switching power systems have generally employed pulse frequency modulation [1],[2].

However, this type of converter has problems, in which a magnetizing current through the converter causes a loss of power under a light load and at stand-by.

For this reason, the small size required for this type of converter cannot be achieved, because an auxiliary source is necessary at standing-by. To solve these problems, a multi-oscillated converter is proposed [3]-[5].

In this paper, a new current resonant type power supply system is devised in which two driving methods are employed. In these driving methods, one MOSFET $\mathrm{Q}_{2}$ as a high-side main switch is driven by an auxiliary winding of the transformer and another MOSFET $\mathrm{Q}_{1}$ as a low-side main switch is driven by the driving IC with a low withstand voltage. The experiment results agree well with simulated results.

\section{Circuit CONFiguration AND OPERATING PRINCIPLE}

Figure 1 and 2 show the newly proposed multi-oscillated current resonant DC-DC converter and the timing chart, respectively.

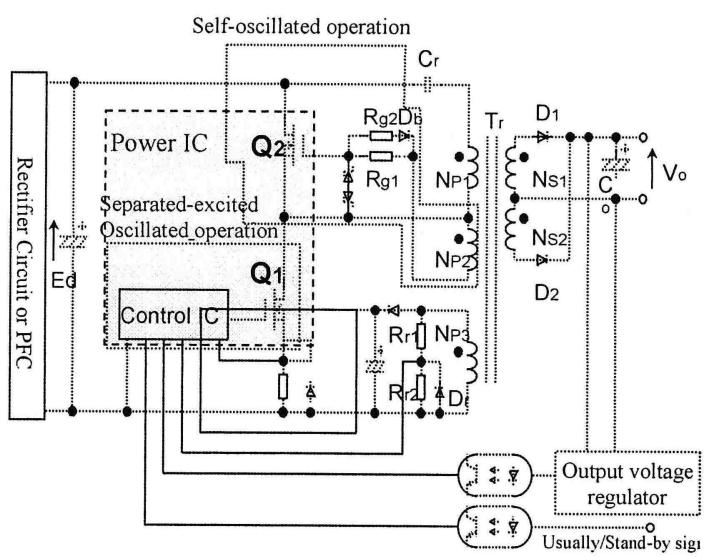

Fig. 1 Proposed multi-oscillated current resonant type DC-DC converter 


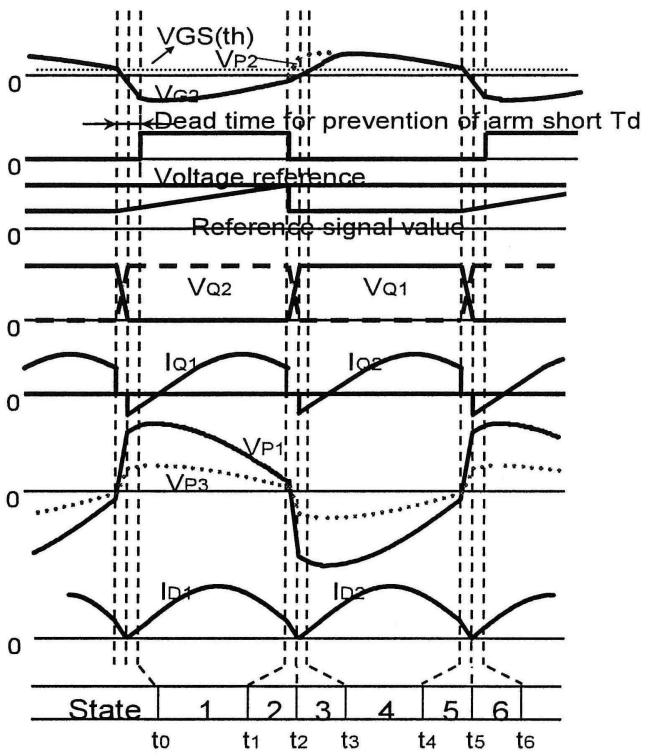

Fig. 2 Timing chart

This converter consists of a half-bridge circuit, which switches $\mathrm{Q}_{1}$ and $\mathrm{Q}_{2}$ are operated by a multi-oscillated current resonant driven by an IC with pulse-width modulation (PWM), and an auxiliary winding of the transformer, respectively.

By applying a gate voltage to $\mathrm{Q}_{1}$ and $\mathrm{Q}_{2}$ at turn-on and turn-off, switching power losses do not occur due to zero-voltage switching (ZVS) and zero-current switching (ZCS).

In the isolated transformer, the winding $N_{P 1}$ is loosely coupled to $\mathrm{N}_{\mathrm{P} 1}$ and $\mathrm{N}_{\mathrm{S} 3}$, for which the voltage of the leakage inductance is relatively large. Depending on the composition of the resonant circuit with this leakage inductance and the resonant capacitor, the switching power losses of $\mathrm{Q}_{1}$ and $\mathrm{Q}_{2}$ are reduced.

The secondary side of the transformer winding is composed of a center-tapped transformer, rectification diodes $\left(D_{1}\right.$ and $\left.D_{2}\right)$ that rectify the high frequency $A C$ voltage for the full wave, and an output capacitor $\left(\mathrm{C}_{\mathrm{o}}\right)$ that smoothes the output voltage.

The control winding $\left(\mathrm{N}_{\mathrm{P} 3}\right)$ used to control the supply source is densely coupled to the primary winding $\left(\mathrm{N}_{\mathrm{P} 1}\right)$.

The voltage $V_{P 1}$ across the primary winding of the transformer is indirectly detected with the voltage across the $\mathrm{N}_{\mathrm{P} 3}$ winding, and is converted to the signal level of the control IC.

The resistors and diode connected between the driving winding $\mathrm{N}_{\mathrm{P} 2}$ and the gate of MOSFET $\mathrm{Q}_{2}$ prevent the short circuit current from simultaneously passing through $\mathrm{Q}_{1}$ and $\mathrm{Q}_{2}$ by varying the gate voltage, slowly at the time of turn-off and at turn-off rapidly.

The output voltage is controlled by feedback, in which the input into the control IC is the voltage command value of the output signal from the output control circuit isolated by a photo coupler.

After the control IC detects the timing for $V_{\mathrm{P} 1}$ to cross from a negative to positive value, $Q_{1}$ is turned on after passing the short-circuit prevention period.

\section{ANALYSIS OF STATES AND OPERATING MODES}

\section{A. Operating State}

In this chapter, the operating modes are analyzed by the simulation and experiment. The following assumptions are made for analysis of the operating modes. Figure 3 shows the equivalent circuit of the converter given in Fig. 1.

(1) The switches $\left(Q_{1}, Q_{2}\right)$ and diodes behave as ideal switches and diodes.

(2) The transformer winding $\left(\mathrm{N}_{\mathrm{P}}, \mathrm{N}_{\mathrm{S}}\right)$ and inductance $\left(\mathrm{L}_{\mathrm{r}}, \mathrm{L}_{\mathrm{m}}\right.$ and $\mathrm{L}_{1}$ ) have negligible loss. Also, the transformer core does not saturate, and each inductance is kept constant.

(3) The resonant capacitor $\left(\mathrm{C}_{\mathrm{r}}\right)$ and the output capacitor $\left(\mathrm{C}_{\mathrm{o}}\right)$ are zero in the serial equivalent circuit.

(4) The voltage across the output of the PFC is represented as the intermediate voltage $E_{\mathrm{d}}$.

Furthermore, the capacitor $\left(\mathrm{C}_{\mathrm{Q} 1}-\mathrm{C}_{\mathrm{Q} 2}\right)$ and the diodes $\left(\mathrm{D}_{\mathrm{Q}_{1}}-\mathrm{D}_{\mathrm{Q}_{2}}\right)$ are shown as the output capacitance of $\mathrm{Q}_{1}-\mathrm{Q}_{2}$ and the body diodes of $\mathrm{Q}_{1}-\mathrm{Q}_{2}$, respectively.

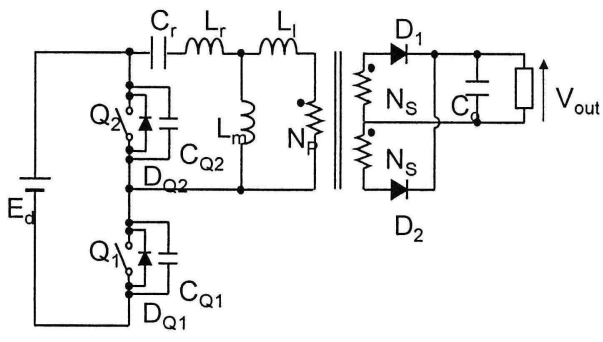

Fig. 3 Equivalent circuit 
The transformer is dealt with by taking into account the leakage inductance between $\mathrm{L}_{\mathrm{r}}-\mathrm{L}_{1}$ and the magnetizing of $\mathrm{L}_{\mathrm{m}}$. The equivalent circuit given in Fig. 3 is divided into eight behavior states with physical meaning, which are given in Table 1 , according to the combination of on and off for $\mathrm{Q}_{1}, \mathrm{Q}_{2}$, and the diodes $\mathrm{D}_{\mathrm{Q} 1}, \mathrm{D}_{\mathrm{Q} 2}, \mathrm{D}_{1}$, and $\mathrm{D}_{2}$.

TABLE 1 States of BeHAVIOR

\begin{tabular}{|c|c|c|c|c|c|c|}
\hline State & $Q_{1}$ & $Q_{2}$ & $D_{Q 1}$ & $D_{Q 2}$ & $D_{1}$ & $D_{2}$ \\
\hline 1 & on & off & off & off & on & off \\
\hline 2 & off & off & off & off & on & off \\
\hline 3 & off & off & off & on & off & on \\
\hline 4 & off & on & off & off & off & on \\
\hline 5 & off & off & off & off & off & on \\
\hline 6 & off & off & on & off & on & off \\
\hline 7 & off & on & off & off & off & off \\
\hline 8 & on & off & off & off & off & off \\
\hline
\end{tabular}

TABLE2 OPERATION MODES

\begin{tabular}{|c|c|}
\hline Mode & State sequence \\
\hline I & $1 \rightarrow 2 \rightarrow 7 \rightarrow 5 \rightarrow 6$ \\
\hline II & $1 \rightarrow 2 \rightarrow 4 \rightarrow 7 \rightarrow 5 \rightarrow 6$ \\
\hline III & $1 \rightarrow 2 \rightarrow 3 \rightarrow 4 \rightarrow 5 \rightarrow 6$ \\
\hline IV & $1 \rightarrow 8 \rightarrow 2 \rightarrow 3 \rightarrow 4 \rightarrow 5 \rightarrow 6$ \\
\hline
\end{tabular}

Taking into account the combination of the eight states of behavior given in Table 1, they are further divided into four operating modes as given in Table 2 .

Figure 4 (a)-4(h) show the current route for each of the operating states. The relations between the time chart (Fig. 2) and the equivalent circuit given in Fig. 4 are explained as follows:

\section{(i) State $1\left(\mathbf{t}_{0}-\mathbf{t}_{1}\right)$}

In this state, before instant $t_{0}$, the switches $Q_{1}$ and $Q_{2}$ turn on and turn off, respectively. Resonant current flows through the series resonant circuit consisting of the resonant capacitor $\left(\mathrm{C}_{\mathrm{r}}\right)$, the leakage inductors $\left(\mathrm{L}_{\mathrm{r}}\right.$ and $\left.\mathrm{L}_{1}\right)$ and the magnetizing inductor $\left(\mathrm{L}_{\mathrm{m}}\right)$ by resonant operation of the converter between $\mathrm{C}_{\mathrm{r}}, \mathrm{L}_{\mathrm{r}}, \mathrm{L}_{1}$ and $\mathrm{L}_{\mathrm{m}}$.

At this time the diode $\left(D_{1}\right)$ of the secondary side conducts the energy transferred to the output side.

As a result, the energy is charged into $\mathrm{C}_{\mathrm{r}}$ and is stored into $\mathrm{L}_{\mathrm{r}}, \mathrm{L}_{1}$ and $\mathrm{L}_{\mathrm{m}}$.

\section{(ii) State $2\left(\mathbf{t}_{1}-\mathbf{t}_{2}\right)$}

The timing of the $\mathrm{Q}_{1}$ turn-off is obtained when the reference voltage is larger than the command voltage, and the reference voltage signal increases in proportion to the time that the auxiliary winding of the transformer reverses to the positive part.

The voltage command value is determined by feedback of the output voltage error from the secondary winding. In this state, the converter operates resonantly by both the series-parallel resonant of the capacitors $\mathrm{C}_{\mathrm{Q} 1}-\mathrm{C}_{\mathrm{Q} 2}-\mathrm{C}_{\mathrm{r}}$, and the resultant of the inductor $\mathrm{L}_{\mathrm{r}}-\mathrm{L}_{\mathrm{m}}-\mathrm{L}_{\mathrm{l}}$, which charges $\mathrm{C}_{\mathrm{Q} 1}$ by the stored energy in $\mathrm{L}_{\mathrm{r}}-\mathrm{L}_{1}-\mathrm{L}_{\mathrm{m}}$, and also $\mathrm{C}_{\mathrm{Q} 2}$ is also discharged.

The resonant current $\mathrm{I}_{\mathrm{cr}}$ is the resultant of current through $\mathrm{C}_{\mathrm{Q} 1}$ and $\mathrm{C}_{\mathrm{Q} 2}$, and so each current is equal.

Therefore, the voltage build-up rate of $\mathrm{Q}_{1}$ and the voltage drop rate of $\mathrm{Q}_{2}$ are suppressed by the discharge speed of $\mathrm{C}_{\mathrm{Q} 1}$, and the charge speed of $\mathrm{C}_{\mathrm{Q} 2}$, respectively.

\section{(iii) State $3\left(t_{2}-t_{3}\right)$}

When the voltage across $C_{Q 1}$ reaches the output voltage $\left(E_{d}\right)$ of $P F C$, the body diode $\left(D_{Q_{2}}\right)$ conducts and the voltage of $\mathrm{Q}_{2}$ is clumped at the voltage $\mathrm{E}_{\mathrm{d}}$.

Also, because part of the stored energy in the magnetizing inductance flows reversely through the series resonant circuit, the secondary diode turns on.

Furthermore, in this state, ZVS and ZCS are achieved depending on whether $\mathrm{Q}_{2}$ is turned on when the current flows through $\mathrm{D}_{\mathrm{Q} 2}$.

\section{(iv) State $4\left(t_{3}-t_{4}\right)$}

When the voltage $V_{P 2}$ across the driving winding of the transformer reverses to the positive part, switch $\mathrm{Q}_{2}$ is turned on slowly and the current of the primary side flows reversely through the serial resonant circuit, in which the turn-on speed of switching $\mathrm{Q}_{2}$ is determined by time constant depending on the resistor $\mathrm{R}_{\mathrm{g} 1}$ between the driving winding $\mathrm{N}_{\mathrm{P} 2}$ and the gate of $\mathrm{Q}_{2}$. The gate voltage $\mathrm{V}_{\mathrm{G} 2}$ is varied by the time constant. As a result, $D_{2}$ conducts, the energy is transferred to the output, $C_{r}$ is simultaneously discharged into $\mathrm{L}_{\mathrm{r}}, \mathrm{L}_{\mathrm{m}}$ and $\mathrm{L}_{1}$.

\section{(v) State $5\left(t_{4}-t_{5}\right)$}

When the voltage $V_{\mathrm{P} 3}$ across the auxiliary winding of the transformer reverses to the positive part, then the timing causes switch $\mathrm{Q}_{2}$ to turn off and switch $\mathrm{Q}_{1}$ to turn on. The resonant behavior in this state is in agreement with the behavior in State 2; that is, $\mathrm{Q}_{2}$ replaces $\mathrm{Q}_{1}$ and $\mathrm{Q}_{1}$ replaces $\mathrm{Q}_{2}$.

\section{(vi) State $6\left(t_{5}-t_{6}\right)$}

The behavior of State 6 is the same as that for State 3, in which replaces $\mathrm{Q}_{2}$ replaces $\mathrm{Q}_{1}$, and $\mathrm{Q}_{1}$ replaces $\mathrm{Q}_{2}$. 


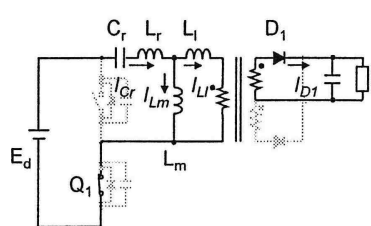

(a) State1

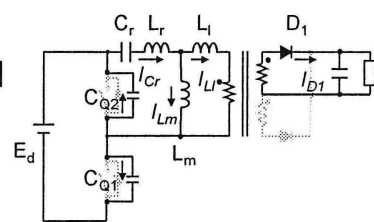

(b) State2

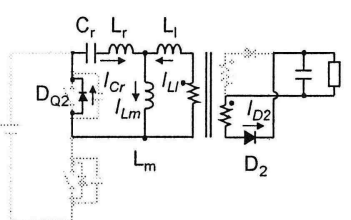

(c) State3

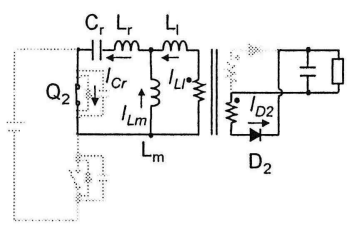

(d) State4

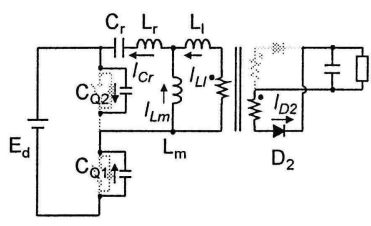

(e) State5

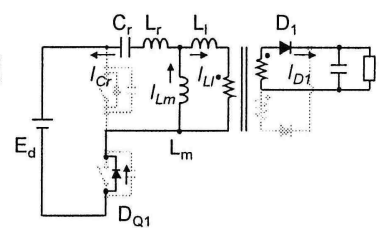

(f) State6

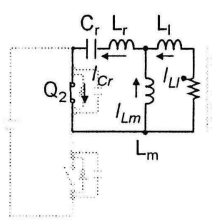

(g) State7

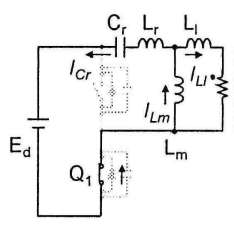

(h) State8

Fig. 4 Equivalent circuit for states of behavior in the converter

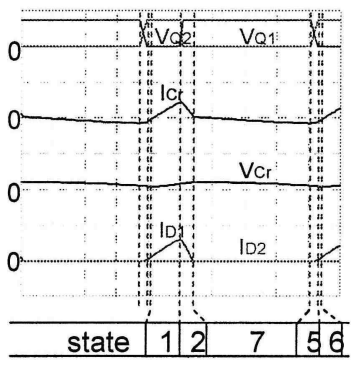

(a) Mode I

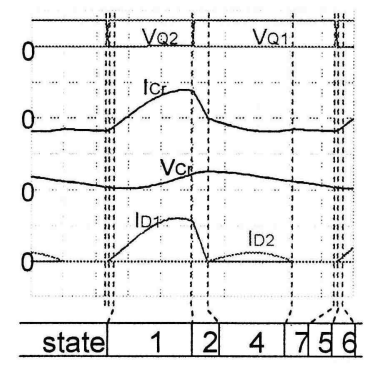

(b) Mode II

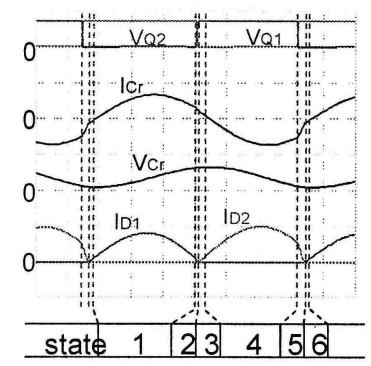

(c) Mode III

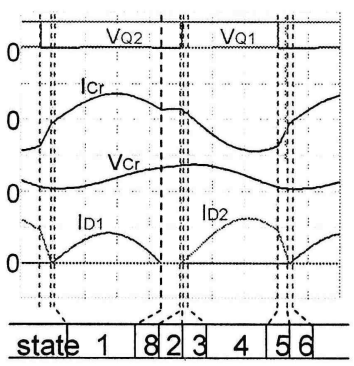

(d) Mode IV

Vertical $\mathrm{V}_{\mathrm{Q} 1}, \mathrm{~V}_{\mathrm{Q} 2}, \mathrm{~V}_{\mathrm{cr}}: 500 \mathrm{~V} / \mathrm{div}, \mathrm{I}_{\mathrm{Cr}}: 2 \mathrm{~A} / \mathrm{div}, \mathrm{I}_{\mathrm{D} 1}, \mathrm{I}_{\mathrm{D} 2}: 10 \mathrm{~A} / \mathrm{div}$

Fig. 5 Simulation waveforms

(vii) State $7\left(\mathbf{t}_{6}-\mathbf{t}_{7}\right)$

This state appears in both Modes I and II. The energy cannot be discharged to the secondary side, because the stored energy in $\mathrm{C}_{\mathrm{r}}$ is small, so that $\mathrm{Q}_{2}$ turns on. As a result, $\mathrm{D}_{2}$ is turned off.

(viii) State $8\left(\mathbf{t}_{7}-\mathbf{t}_{\mathbf{8}}\right)$

This state appears in Mode IV. For the resonant behavior that depends on the resultant of combination of $\mathrm{C}_{\mathrm{r}}$, and $\mathrm{L}_{\mathrm{r}}, \mathrm{L}_{\mathrm{m}}$ and $\mathrm{L}_{1}$ due to the large stored energy in $\mathrm{C}_{\mathrm{r}}$, the current flows reversely through the series resonant circuit, and so the circuit takes $\mathrm{L}_{m}$ in reverse bias. As a result, it is the interval for $\mathrm{D}_{1}$ to turn off, because the energy cannot discharge to the secondary side. 


\section{B. Operating Mode}

Figure 5 shows the simulated waveforms of the current and voltage for the four operating mode. The conditions for analysis maintain the input voltage at $360 \mathrm{~V}$ and the output voltage at $24 \mathrm{~V}$. The operating mode is determined from the voltage amplitude in the secondary side diodes of $\mathrm{D}_{1}$ and $\mathrm{D}_{2}$, and the resonant capacitor $\mathrm{C}_{\mathrm{r}}$.

It is found that operating modes appear in the order of I, II, III, IV when the load current is varied from a light load current to the rated load current $6 \mathrm{~A}$ and a heavy load current of $7 \mathrm{~A}$.

Operating Mode I and II mainly appear at light loads. The energy in $C_{r}$ is discharged when the $Q_{1}$ switch turns off and $\mathrm{Q}_{2}$ turns on, and it is charged by applying the output voltage $E_{d}$ of the PFC when the $Q_{1}$ switch turns on.

Therefore, the energy is discharged to the secondary side through the transformer.

However, because the magnetizing inductance $L_{m}$ is set relatively largely when there is shortage of energy discharged from $\mathrm{C}_{\mathrm{r}}$, operating State 7 appears, in which there is no discharging interval to the secondary side.

As a result, the output current does not flow when operating Mode I appears at light load, but is controlled by being applied only from $D_{1}$.

Operating Mode III appears in the vicinity of the rated output. The ripple is reduced and smoothed by the leakage inductance $\mathrm{L}_{1}$ of the secondary winding and the input capacitor $\mathrm{C}_{0}$ because the current flows continuously through $\mathrm{D}_{1}$ and $\mathrm{D}_{2}$. Operating Mode IV appears when the output is larger than the rated output, and when the duty ratio is larger than between $50 \%$ and $60 \%$.

For the purpose of comparing operating Mode IV with other modes, the voltage amplitude of the resonant capacitor $\mathrm{C}_{\mathrm{r}}$ should be considered. Assuming that the voltage amplitude of $\mathrm{C}_{\mathrm{r}}$ is equal to the output voltage $E_{d}$ of the PFC when the maximum output power is applied from $\mathrm{C}_{\mathrm{r}}$ in the converter, the maximum output can be approximated by Eq. (1).

$$
\mathrm{P}\left(\mathrm{C}_{\mathrm{r}}\right)=\mathrm{C}_{r} \cdot E_{d}{ }^{2} \cdot f_{s}
$$

where $L_{r}$ is the resonant frequency, given by

$$
f_{r}=\frac{1}{2 \pi \sqrt{C_{r} \cdot L_{r}}}
$$

where $f_{r}$ is the inductance of primary side at the short-circuit of the secondary winding.

Figures 6 and 7 show the voltage amplitude characteristics of the resonant capacitor $\mathrm{C}_{\mathrm{r}}$, and the output current versus voltage for the experiment, respectively.

From Fig. 6, it is found that the operating mode changes with variation in $\mathrm{V}_{\mathrm{Cr}}$, and that $\mathrm{V}_{\mathrm{Cr}}$ is greater than $\mathrm{Ed}=360 \mathrm{~V}$ at an output current of $7 \mathrm{~A}$

When $V_{C r}$ is greater than $E_{d}$ by varying the output current, State 8 appears, where the power is not applied to the secondary side even when $\mathrm{Q}_{1}$ turns on.

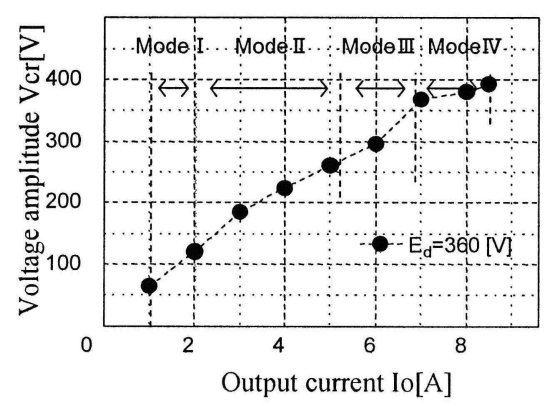

Fig. 6 Voltage amplitude characteristics of resonant capacitor

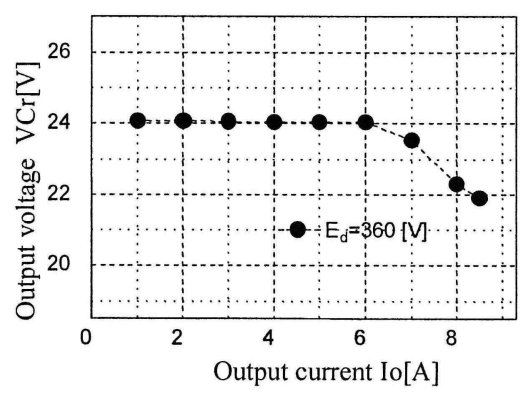

Fig. 7 Output current versus output voltage characteristics

It is for this reason that the operating mode shifts to Mode IV, where the output is smaller than the maximum power. Therefore, it is found that the output voltage is determined by $\mathrm{V}_{\mathrm{Cr}}$. This is representative of the new converter. 


\section{EXPERIMENT RESULT}

In order to verify the operating characteristics the experimental parameters are as follows.

\begin{tabular}{|c|c|}
\hline Output voltage $E_{d}$ of PFC & $360 \mathrm{~V}-400 \mathrm{~V}$ \\
\hline Output voltage $\mathrm{V}_{\mathrm{o}}$ & $24 \mathrm{~V}$ \\
\hline Output current of $I_{0}$ & $1 A-6 A$ \\
\hline Winding ratio & \\
\hline \multicolumn{2}{|c|}{$\mathrm{N}_{\mathrm{P} 1}: \mathrm{N}_{\mathrm{S} 1}\left(=\mathrm{N}_{\mathrm{S} 2}\right) ; \mathrm{N}_{\mathrm{P} 2}: \mathrm{N}_{\mathrm{P} 3}=52: 4: 5: 7$} \\
\hline Resonant Capacitor of $\mathrm{C}_{\mathrm{r}}$ & $22 \mathrm{nF}$ \\
\hline Resonant inductance of $\mathrm{L}_{\mathrm{r}}$ & $130 \mu \mathrm{H}$ \\
\hline Magnetizing inductance of $\mathrm{L}$ & 1664 \\
\hline Output Capacitor of $\mathrm{C}_{\mathrm{o}}$ & $1 \mathrm{n}$ \\
\hline
\end{tabular}

Figures 8 and 9 show the frequency operating characteristics and the duty ratio characteristics, respectively. The circuit is controlled by changing the operating frequency at the same time as PWM.

The operating frequency becomes high when the input voltage is high and the load is light. However, the rate of rise is nearly at $24 \%$.

The reason for this is that the frequency rise is suppressed at a light load, in order to be controlled and dependent on maintaining the duty ratio of the switch $\mathrm{Q}_{2}$ to be approximately constant.

Figure 10 shows the observed waveforms between a light load and the rated load at an input voltage of $380 \mathrm{~V}$.

It is seen that the observed waveforms agree well with the simulated ones. Furthermore, ZVS and ZCS are achieved for the $\mathrm{Q}_{1}$ and $\mathrm{Q}_{2}$ switches.

Figure 11 shows the high power efficiency of $94.7 \%$ when the output current varies from $1 \mathrm{~A}$ to $6 \mathrm{~A}$.

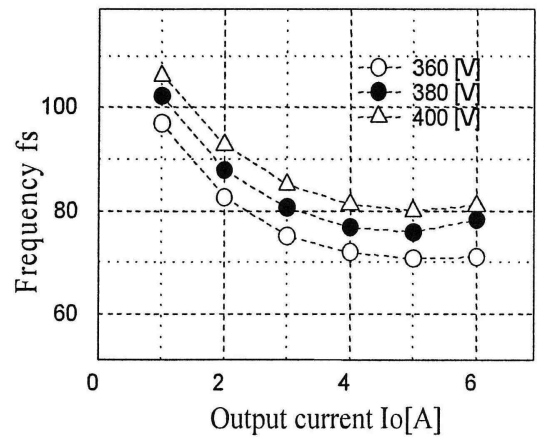

Fig. 8 Output current versus frequency characteristics

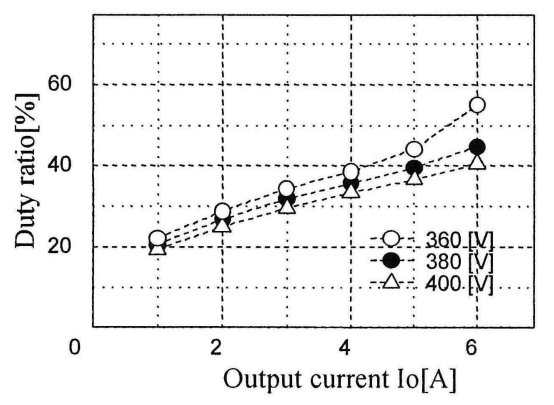

Fig. 9 Output current versus duty ratio characteristics

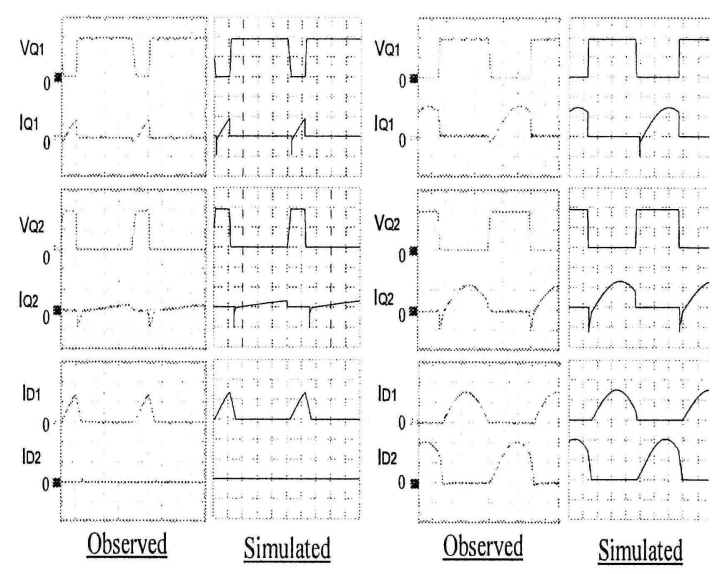

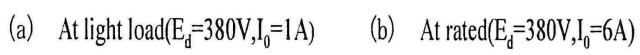

Vertical; VQ1,VQ2 :200V/div, IQ1, IQ2 : 2A/div, IQ1, IQ2 : 5A/div

Fig. 10 Observed waveform

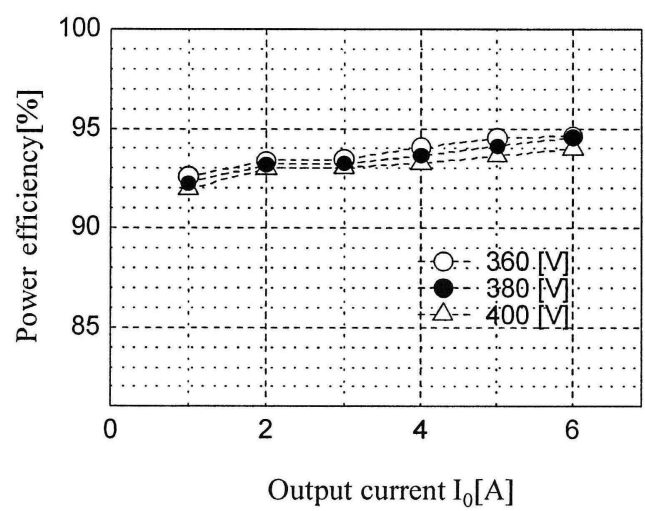

Fig. 11 Output current versus power efficiency 


\section{CONCLUSIONS}

We conclude as follows.

(1) The new converter is controlled by a combination of self-oscillation and a separated oscillation .

(2) This converter has eight states and four operating modes.

(3) When the output power reaches a maximum, the voltage $V_{c r}$ across the resonant capacitor overcomes the voltage $E_{d}$ from the PFC. As a result, the output voltage decreases.

(4) High power efficiency is obtained at an input voltage $360 \mathrm{~V}$, where $94.7 \%$ and $93.4 \%$ are achieved at $24 \mathrm{~V}-6 \mathrm{~A}$ and $24 \mathrm{~V}-2$ A output, respectively.

In order to achieve an improvement of efficiency at light load and minimization of stand-by power at no-load, applications relating to the dependency of the input voltage and load current, and optimization of design for each element, especially the transformer, are currently under study.

The details of these characteristics will be reported in our next paper.

\section{REFERENCES}

[1] K. Morita "Novel Ultra Low-noise Soft Switching-mode Power Supply”, INTELEC'98, pp.115-122, 1998.

[2] K. Kuwahara, H. Ota "On the Output Increase of a Series Resonant DC-DC Converter”, IEICE Technical Report, Vol.105, no.45, EE2005, pp.35-40, 2005

[3] M. Gekinozu, K. Kuroki, K. Mori, T. Fujita "Self-oscillated type current resonant DC/DC converter", IEICE Technical Report, EE99-58, pp.33-38. 2002

[4] Y. Nishikawa, T. Nozawa, S. Igarashi, K. Kuwahara, N. terasawa "Multi-oscillated Current Resonant Converter", Annual Conference Record of EEEJ, Vol.4, pp.157-158, 2002

[5] Y. Nishikawa, T. Nozawa, S. Igarashi, K. Kuwahara, N. Nozawa, $\mathrm{H}$. Ota "A control method that reduce the conversion loss at a light load", Annual Conference of Japan, Industry Application Society, pp.631-632, 2002 